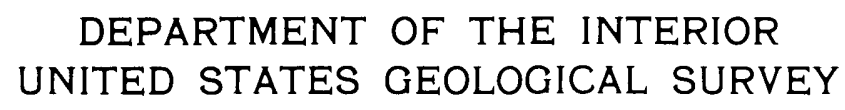

Prepared under the joint sponsorship of the GOVERNMENT OF LIBERIA and the AGENCY FOR INTERNATIONAL DEVELOPMENT

U.S. DEPARTMENT OF STATE

\title{
AEROMAGNETIC MAP \\ OF THE SANOKOLE QUADRANGLE, LIBERIA \\ By
}

John C. Behrendt and Cletus S. Wotorson

FOLIO OF THE SANOKOLE QUADRANGLE, LIBERIA

MAP I-774 B

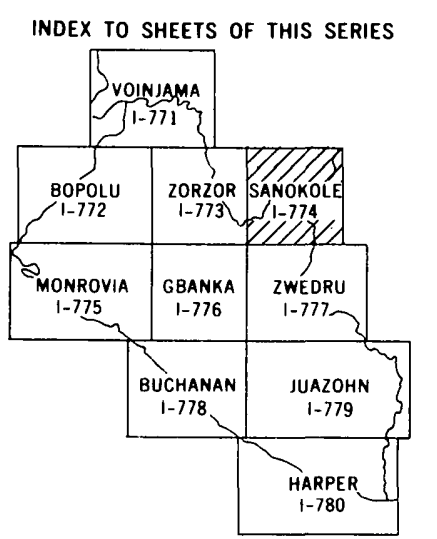

PUBLISHED BY THE U.S. GEOLOGICAL SURVEY

RESTON, VA, 22092 